\title{
Extinction and reacquisition performance alternations of the conditioned nictitating membrane response
}

\author{
MICHAEL J. SCAVIO, JR. \\ California State University, Fullerton, California 92634 \\ and \\ RICHARD F. THOMPSON \\ University of California, Irvine, California 92717
}

\begin{abstract}
The present experiment assessed extinction-reacquisition alternation and retention interval effects upon the performance of the rabbit's classically conditioned nictitating membrane response. The study revealed that the membrane conditioned response (CR) decremental rate on the third extinction set following reacquisition was enhanced. Reacquisition performance of the membrane CR was consistently accompanied by a large savings effect and was not influenced by alternated exposures to extinction. Finally, the imposition of retention intervals in lieu of extinction produced no differential effects upon membrane CR reacquisition. This pattern of results suggests that a conditioned stimulus may simultaneously retain excitatory and inhibitory learning properties with the expression of each determined by the presence (for excitation) and absence (for inhibition) of the unconditioned stimulus.
\end{abstract}

The purpose of the present experiment is to ascertain the performance characteristics of the rabbit's conditioned nictitating membrane response (NM CR) in alternated extinction and reacquisition training cycles. The impetus for this investigation was provided by the earlier work of Smith and Gormezano (1965), who sequentially presented 22 1-day extinction and reacquisition sessions. Their results showed that NM CR performance remained at asymptotic levels across the interspersed reacquisition days, while performance over the extinction days gradually declined, with substantial levels of conditioned responding still evident on the final extinction session. Even though relatively small NM CR performance losses were observed across the extinction sessions, Smith and Gormezano noted an enhancement of the within-sessions decremental rate as the number of previous extinction sessions increased.

In order to establish whether an accelerated betweensessions drop in NMCR extinction performance can be produced, the present experiment, in contrast to the Smith and Gormezano (1965) study, provided several consecutive days of extinction before a reacquisition session was given. By increasing the amount of uninterrupted extinction, a greater opportunity may be afforded for the formation of resilient conditioned

Reprints can be obtained from M. J. Scavio, Department of Psychology, California State University, Fullerton, California 92634. The authors wish to thank Pamela Scavio for her assistance in the completion of the experiment. stimulus (CS) inhibitory effects capable of surviving the imposition of reacquisition and substantially augmenting the between-sessions extinction rate. Moreover, recent theoretical accounts of classical conditioning (Frey \& Sears, 1978; Rescorla, 1975; Rescorla \& Wagner, 1972) have stressed that excitatory and inhibitory learning effects are controlled by opposing symmetrical processes. Thus, the accumulation of excitatory CS strength removes inhibitory CS effects and vice versa. The presently obtained pattern of extinction and reacquisition NM CR performances allows an assessment of the proposed theoretical affiliation between excitation and inhibition.

\section{METHOD}

\section{Subjects}

The subjects were 18 male and female New Zealand albino rabbits (Oryctolagus cuniculus), 90-100 days old; each rabbit weighed approximately $2 \mathrm{~kg}$ at the beginning of the experiment.

\footnotetext{
Apparatus

The recording procedures for the NM CR have been described by Bromage and Scavio (1978), who detail variations in the preparations originally established by Gormezano (1966).

Briefly, six conditioning chambers were fabricated from legal-sized file cabinets, with each ventilated chamber containing a stimulus panel that held two $24-\mathrm{V}$ dc, $10-\mathrm{W}$ lamps mounted behind diffusion glass, so as to provide interior illumination. In addition, the stimulus panel contained a $6.35-\mathrm{cm}$ Quam audio speaker that presented the tone CS. Plexiglas boxes with variable backplates and yoke collars were used to restrain the rabbits during the training sessions. Nictitating membrane movement was monitored by means of a 10-kohm Giannini microtorque potentiometer that converted physical movement
} 
into linear voltage changes. Response analysis was completed by feeding the amplified potentiometer signals into an analogto-digital converter of a PDP-12 computer. During the training sessions, the potentiometer for each rabbit was mounted on a muzzle device that was securely locked to a ring looped over the rabbit's pinnae. From the longer arm of a counterbalanced L-shaped piano-wire lever, a length of silk thread was attached to a 2-mm-diam nylon suture embedded in the right nictitating membrane. The shorter arm of the piano-wire lever was then fastened to the rotary axle of the potentiometer.

The CS was a $500-\mathrm{msec} 1,000-\mathrm{Hz}$ tone of $84 \mathrm{~dB}$ (re 20 $\mu \mathrm{N} / \mathrm{m}^{2}$ ) superimposed on a $72-\mathrm{dB}$ white-noise field. The unconditioned stimulus (US) was a $50-\mathrm{msec}, 4-\mathrm{mA}, 60-\mathrm{Hz}$, electrical shock delivered through alligator clips embedded in the skin $10 \mathrm{~mm}$ apart and $15 \mathrm{~mm}$ behind the right eye. The presentation of the stimuli, as well as the recording of the membrane response, was under the control of the PDP-12 computer, with the necessary software described elsewhere (Bissell \& Scavio, 1974).

\section{Procedure}

Two days after arrival, each rabbit received a suture in the right nictitating membrane made with 00 monofilament nylon thread. On Day 2 after suturing, six rabbits each were assigned to one of three groups and adapted to the conditioning apparatus. In adaptation, each group was housed in the apparatus for $40 \mathrm{~min}$. On Day 3 following suturing, initial NM CR acquisition training was administered to all groups. Group $E$ received 3 consecutive days of acquisition training, followed by 3 days of extinction, 1 day of reacquisition, 3 days of extinction, 1 day of reacquisition, 6 days of extinction, and a final set of reacquisition trials administered immediately upon the completion of the last extinction trial. Group $\mathbf{R}$ was treated as Group $\mathrm{E}$, except that 3 -day retention intervals were employed in lieu of the intermediate 3-day extinction series given to Group E. Thus, Group $\mathbf{R}$ was sequentially exposed to 3 days of acquisition, 3 days of rest in the home cages without any training (retention interval), 1 day of reacquisition, 3 days of rest in the home cages without training (retention interval), 1 day of reacquisition, and 6 days of extinction. Following the last extinction trial on Day 6, a final set of reacquisition trials was also given to Group $\mathbf{R}$. Group $\mathbf{N}$ did not receive repetitive cycles of extinction and reacquisition as administered to Group E. Instead, 5 consecutive acquisition days were given to Group $\mathrm{N}$, followed by 6 extinction days. As for Groups $\mathrm{E}$ and $\mathrm{R}$, Group $\mathrm{N}$ also obtained the final set of reacquisition trials beginning upon the completion of the last extinction trial. Although the groups differed in the distribution of CS-US pairings (for acquisition and reacquisition), the amount of extinction received, and the use of retention intervals, they were exposed to the same number of CS-US pairings.

For all groups, each acquisition and reacquisition day consisted of 80 CS-US pairings, whereas each extinction day required $80 \mathrm{CS}$-alone deliveries. The final set of reacquisition trials given on the same day following the completion of the last extinction trial consisted of $40 \mathrm{CS}$-US pairings. The CS-US interval on paired trials was $500 \mathrm{msec}$. The intertrial intervals for paired and extinction trials were randomized at values of 50,60 , and $70 \mathrm{sec}$. The time separation between the last extinction trial and the beginning of the final set of reacquisition trials was $1 \mathrm{~min}$. A membrane extension of at least $1 \mathrm{~mm}$ occurring during the $500-\mathrm{msec} \mathrm{CS}$ duration on paired and extinction trials was scored as a CR.

\section{RESULTS}

Groups $\mathrm{E}$ and $\mathrm{R}$ were initially exposed to 3 consecutive days of acquisition training, while Group $\mathrm{N}$ began with 5 consecutive acquisition days. On Day 3 of acquisition, all groups reached asymptotic NM CR performance levels of $95 \%$ response rate on the conditioning trials. Group $\mathrm{N}$ continued to maintain the asymptote on its 2 additional days of training. An analysis of variance performed for all groups upon percentage of NM CRs in 20-trial blocks over the initial 3 days of acquisition revealed significant effects for days $[F(2,30)=192.89, p<.01]$, blocks $[F(3,45)=26.43$, $\mathrm{p}<.01]$, and the Days by Blocks interaction $[\mathrm{F}(6,90)=$ $5.54, \mathrm{p}<.01]$. The groups effect was not significant. These findings indicated that all groups showed similar between- and within-sessions increments in NM CR performance, with the major portion of the improvement occurring on earlier as opposed to later training trials. Finally, an analysis of variance was conducted upon the group percentage of NM CRs in 20-trial blocks on the final day of acquisition (Day 3 for Groups $E$ and $\mathrm{R}$; Day 5 for Group N). The analysis yielded no reliable effects, which substantiated that all groups performed similarly on the final acquisition session.

Figure 1 shows, for all groups, the percentage of NM CRs recorded during the extinction and reacquisition sessions of the experiment. Group E, which received alternated extinction and reacquisition, displayed conspicuous changes in its NM CR performance over the sessions constituting the three extinction sets. A comparison involving each of the initial days of the three extinction sets, with each initial day following the completion of a membrane training session, reveals an acceleration of the declinatory rate in NMCR performance. Thus, on each of the initial days of the first and second extinction sets, $75 \%$ and $65 \%$ NM CR levels were recorded; however, on Day 1 of the third extinction set, NM CR performance dropped to $34 \%$.

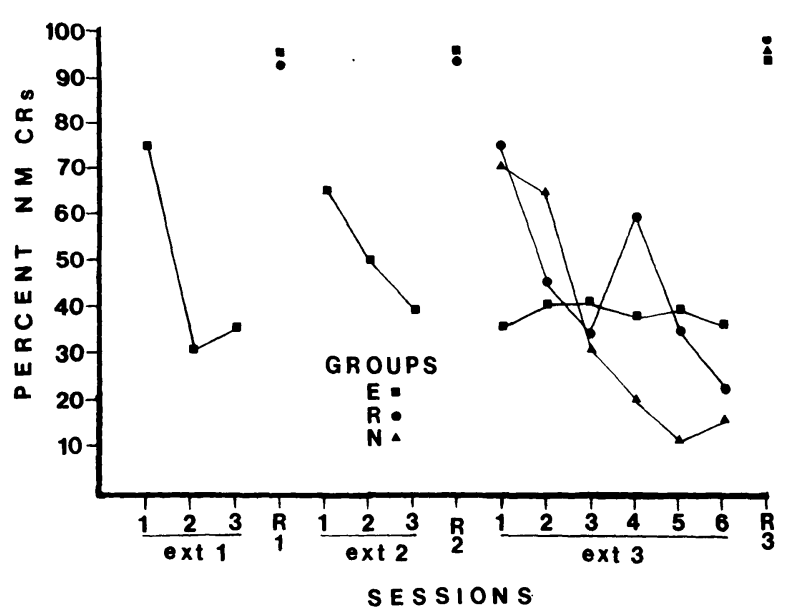

Figure 1. Percentage of nictitating membrane conditioned responses (NM CRs) shown for Groups $E$, $R$, and $\mathbf{N}$ over the extinction and reacquisition sessions of the experiment. The sessions constituting each of the three extinction sets (ext) are numerically designated, as are each of the reacquisition (R) sessions. 
Moreover, as Group E was exposed to the remaining days of the third extinction set, a relatively invariant NM CR performance gradient was obtained. In contrast, Groups $\mathrm{R}$ and $\mathrm{N}$, which received their only extinction during the experiment's third extinction set, produced more conventional negatively sloped extinction gradients. It also should be noted that Group R, which received two 3-day retention intervals in lieu of the first two extinction sets, produced a more jagged extinction gradient than Group N, which received the 6 days of extinction upon the completion of 5 acquisition training days.

Figure 1 also depicts the NMCR performance in the various reacquisition sessions. Thus, Group E, which obtained the three reacquisition sessions, with each session given upon the completion of an extinction set, consistently showed the return of the NMCR acquisition performance asymptote. Group $R$, which had retention intervals in place of the first two extinction sets but received the third extinction set, cannot be distinguished from Group E's reacquisition performances. Finally, Group N, which obtained only the last reacquisition following the 6-day extinction set, also performed similarly to Groups E and R. A further analysis of the three reacquisition sessions revealed that no group required more than an average of three CS-US pairings before all subjects resumed conditioned responding. In addition, the groups consistently showed the asymptotic return of the NMCR performance within the first 20 CS-US pairings of each reacquisition. Finally, the rapidity in the reestablishment of the NM CR performance asymptote was not affected by delaying the start of CS-US pairings for $24 \mathrm{~h}$ (as was done for the first and second reacquisition sessions) or administering CS-US pairings beginning $1 \mathrm{~min}$ following the termination of extinction (as was done for the third reacquisition session).

An analysis of variance upon percentage of NM CRs in 20-trial blocks was completed for Group $\mathrm{E}$ on the initial days of the three extinction sets. The analysis revealed a significant days factor $[F(2,10)=11.52$, $\mathrm{p}<.01$ ] . Orthogonal tests upon the performance means for each of the 3 days found that responding on Day 1 of the third extinction set (mean $=.35$ ) was significantly lower $\left(F_{s}<.01\right)$ than that obtained on the initial days of the first (mean $=.75$ ) and second (mean $=.65$ ) extinction sets, with no reliable difference between the latter two performances. Thus, repeated daily exposure to extinction before the implementation of reacquisition allowed for the development of an accelerated between-sessions drop in the NMCR extinction performance. The analysis also presented a significant blocks factor $[F(3,15)=66.07, p<.01]$, which indicated that Group E displayed expected within-sessions decrements in extinction. However, since no significant Blocks by Days interaction was obtained, the analysis did not provide any evidence for changes in the within-sessions decremental rate as a function of prior extinction exposure.

Another analysis of variance was completed for all groups upon the percentage of NM CRs in 20-trial blocks over the 6 days of the final extinction set. Significant effects were obtained for days $[F(5,75)=8.35$, $\mathrm{p}<.01]$, blocks $[\mathrm{F}(3,45)=47.56, \mathrm{p}<.01]$, and the Groups by Days interaction $[\mathrm{F}(10,75)=4.27$, $p<.01]$. The blocks factor supported the expected occurrence of within-sessions decrements in performance. The days factor, coupled with the Groups by Days interaction, indicated that the shape of the daily extinction curves differed for the groups. The interaction was traced to the relatively flat performance curve exhibited by Group E relative to those shown by Groups $\mathrm{R}$ and $\mathrm{N}$, since an analysis of variance for the latter two groups revealed no reliable effects for groups, days, or blocks of training trials. These findings support the observation that prior extinction exposures produced persistent inhibitory effects upon the course of subsequent conditioned responding in extinction.

Finally, appropriate analysis of variance tests were completed for the groups upon the percentage of NM CRs in 20-trial blocks on the three reacquisition sessions. These analyses revealed no significant effects, which corroborates the observation that the return of the NM CR performance asymptote was very rapid in reacquisition and was not affected by the administration of prior extinction, retention intervals, or extinction-reacquisition time separation.

\section{DISCUSSION}

The present experiment investigated the effects of alternating extinction and reacquisition training upon the performance of the NMCR. A comparison of the NMCR performance rate on the initial days of the three extinction sets, with each set separated by reacquisition, revealed an acceleration in the between-sessions declinatory rate. In addition, the performance gradient over the remaining days of the third extinction set was relatively invariant and thereby departed from conventional negatively sloped gradients for groups receiving extinction for the first time. Finally, repeated reacquisition sessions, given following either extinction or retention intervals, consistently produced the rapid return of the NMCR performance asymptote. The reinstatement of the NM CR asymptote was not affected by the number of prior extinction exposures, time separation between the conclusion of extinction and the initiation of reacquisition $(24 \mathrm{~h}$ vs. $1 \mathrm{~min})$, or any timedependent process associated with the imposition of retention intervals.

The observation regarding the development of an accelerated between-sessions extinction rate serves to extend the previous work of Smith and Gormezano (1965), who alternated extinction and reacquisition on a daily basis. In our work, the appearance of a between-sessions increase in the extinction rate was apparently due to the employment of several consecutive extinction sessions before reacquisition was undertaken. Consequently, a favorable opportunity was afforded for the accumulation of resilient CS inhibitory effects which, by surviving reacquisition, hastened the subsequent extinction of the NMCR. The consistently strong reacquisition performance of the NMCR also indicates that excitatory CS 
properties, originally acquired in acquisition, remained impervious to potentially counteractive effects of repeated extinction or retention intervals in lieu of extinction. Thus, the data are supportive of the proposal that a CS can simultaneously maintain both excitatory and inhibitory properties. The release of excitatory and inhibitory effects upon behavior, then, presumably involves the receipt (for excitation) or omission (for inhibition) of the US. The possibility of dual excitatory and inhibitory CS attributes represents a theoretical departure from the central premise of current conditioning models (Frey \& Sears, 1978; Rescorla, 1975; Rescorla \& Wagner, 1972), proposing that the accumulation and maintenance of excitation and inhibition are mutually antagonistic. Therefore, a further elaboration of extinction-reacquisition effects may be useful in clarifying the interrelationship of excitatory and inhibitory CS effects.

\section{REFERENCES}

Bissell, H. S., \& Scavio, M. J., JR. A minicomputer program for the resolution of response frequency and latency in classical conditioning preparations. Behavior Research Methods \& Instrumentation, 1974, 6, 439-442.

Bromage, B., \& Scavio, M. J., JR. Effects of an aversive CS+ and CS- under deprivation upon successive classical appetitive and aversive conditioning. Animal Learning \& Behavior, 1978, 6, 57-65.

FreY, P. W., \& SEARS, R. J. Model of conditioning incorporating the Rescorla-Wagner associative axiom, a dynamic attention process, and a catastrophe rule. Psychological Review, 1978, 85, 321-340.

Gormezano, I. Classical conditioning. In J. B. Sidowski (Ed.), Experimental methods and instrumentation in psychology. New York: McGraw-Hill, 1966.

Rescorla, R. A. Pavlovian excitatory and inhibitory conditioning. In W. K. Estes (Ed.), Handbook of learning and cognitive processes: Conditioning and behavior theory (Vol. 2). Hillsdale, N.J: Erlbaum, 1975.

Rescorla, R. A., \& WAgner, A. R. A theory of Pavlovian conditioning: Variations in the effectiveness of reinforcement and nonreinforcement. In A. H. Black \& W. F. Prokasy (Eds.), Classical conditioning II: Current theory and research. New York: Appleton-Century-Crofts, 1972.

Smith, M., \& Gormezano, I. Effects of alternating classical conditioning and extinction sessions on the conditioned nictitating membrane response of the rabbit. Psychonomic Science, $1965,3,91-92$.

(Received for publication November 1, 1978.) 